\title{
THE NATURE OF THE INTERNAL SECRETION OF THE PANCREAS.
}

By W. M. Crofton, M.D., Lecturer in Special Pathology, Univ. Coll., Dublin.

An Hypothesis.

$T^{\mathrm{T}}$ is no exaggeration to state that the question of the 1 relation of the internal secretion of the pancreas to. metabolism is in a state of confusion and still more confused are our ideas of its nature. The object of this essay is to attempt to show that this substance is not, as is usually held, a 'hormone' such as the secretins, thyroid substance, pituitrin, and so on, but is an essential part of a compound ferment by means of which synthesis and hydrolysis, that is, anabolism and katabolism of different food material, is brought about.

It will not be possible for me to give anything like a complete account of all the work that has been done; it will only be possible to give a general outline and to meet and explain the objections which appear hostile to my hypothesis.

Von Mering and Minkowski first showed that the complete removal of the pancreas produced a severe and rapidly fatal diabetes in which there was profound upset of both carbohydrate, fat and protein metabolism. That this was not. due to absence of the external secretions (protease, lipase, amylase) was shown by the fact that if a portion of the pancreas is grafted under the skin these metabolic errors. constituting diabetes do not occur.

It is to be noted that glycogen entirely disappears from these animals.

There is imperfect metabolism of fats with the production of poisonous fatty acids, and there is a rapid breakdown of the cell proteins with formation of ammonia to neutralise these fatty acids.

Cohnheim showed that if muscle press-juice or pancreas press-juice was mixed with a solution of dextrose little or no sugar disappeared, but that if pancreas press juice was added there was a very marked decrease in its copper- 
reducing power, e.g., samples of mixed juice acting on $2 \%$ dextrose caused a reduction in its copper-reducing power of $.35 \%$ to $.84 \%$, while the muscle juice alone under similar conditions caused from 0 to $0.021 \%$ reduction of this power.

Others failed to get these results, obtaining marked reduction with muscle juice alone, but it was shown by Hall that this was due to the muscles not being properly washed free from blood which contains the necessary substance. Moreover, the suggestion that the reduction was due to microbial action has proved not to be the case, as the experiments were repeated under aseptic and antiseptic conditions. It has been found that the experiment does not succeed if the muscle juice is first heated to $60^{\circ}$ Centigrade, while an extract of a boiled pancreas will provide its necessary substance. That is, the muscle substance is, in the language of imnunology, heat-labile, while that in the pancreas juice is heat-stable.

The disappearance, then, of the glucose in the experiment is brought about by the interaction of a heat-labile substance obtained from tissue cells and a heat-stable substance obtained from the pancreas.

It was natural to suppose that the copper-reducing power in Cohnheim's original experiment and that of his repeaters was due to the breakdown of the glucose into its elements under the conditions of the experiment. This appears not to be the case. The disappearance of this power bas been shown (Levene and Meyer) to be due to the glucose being claborated into a non-reducing saccharide. According to Bayliss this entirely destroys the significance of the experiment, but it seems to me capable of a simple explanation, viz., that just as in the next experiments to be referred to, it is due to the too great concentration of glucose in the experiment as in the intact body of the concentration of glucose is above $0.2 \%$ glycogen is stored in the liver and muscle cells; if it falls below this glycogen is broken down to keep the glucose concentration in the blood and tissue fluids normal-the internal secretion of the pancreas being necessary for both these operations.

Knowlton and Starling using heart-lung preparations showed that a preparation made from a depancreatised dog 
had little or no capacity for metabolising glucose unless pancreatic extract were added to the Ringer's solution. On repeating these experiments it was shown that the disappearance of the sugar was due to its elaboration into glycogen in the heart-muscle. The conclusion from the past experiments that the internal secretion had produced hydrolysis of the glucose was therefore abandoned. It is to be noted that the percentage of sugar in the circulating fluid in these experiments was generally above $.2 \%$. Clark, however, using a heart-pancreas preparation and taking elaborate care against microbial contamination, has shown that:-

(1) If the pancreas was perfused alone with Ringer-Locke solution, no dextrose had. disappeared at the end of four hours. If the heart were perfused alone, $0.7 \mathrm{mg}$ of dextrose had been used por gramme of heart. If the Ringer-Locke was perfused through both the pancreas and heart nearly $2 \mathrm{mg}$. per gramme of heart had disappeared. Hydrolysis at the end of the experiment showed that .175 (about) mg. of this disappearance was due to the formation of a polysaccharide.

(2) If the fluid was first perfused through the pancreas for 15-60 minutes there was no utilisation of dextrose, but if the pancreas was then removed from the apparatus and the heart of the same dog substituted and the fluid perfused for 4 hours through it, $2.6 \mathrm{mg}$. per gramme of heartmuscle was used; $0.6 \mathrm{mg}$. per gramme of this disappearance was due to the formation of a polysaccharide.

(3) If the pancreatic perfusate was first heated to boiling this marked utilisation did not take place, but it stood heating to $56^{\circ} \mathrm{C}$., nor did it take place if the heart was not beating.

(4) If different amounts of pancreas perfusates were added different amounts of dextrose were used, e.g., if 1 cc. were added $1.4 \mathrm{mg}$. of dextrose was used in four hours per gramme of heart-muscle, and no polysaccharide was formed. If 5 cc. of pancreas perfusate was added nearly $1.8 \mathrm{mg}$. per gramme was used and $.1 \mathrm{mg}$. per gramme of polysaccharide. If $10 \mathrm{cc}$. of perfusate was added $3 \mathrm{mg}$. per gramme was used, and nenrly $0.175 \mathrm{mg}$. of polysaccharide per gramme formed. 
The concentration of the dextrose in these experiments was always below $0.5 \%$.

Clark concludes that the substance is of the nature of a ferment.

It is quite clear from these experiments that the pancreas perfusate brings about both an hydrolysis and a polymerisation of dextrose.

Héden has produced similar results in live dogs. Anastomosis was made between the pancreatic vein of a normal dog and the jugular vein of a depancreatised and diabetic dog. The glycosuria almost disappeared, and there was a diminution in the glucose-content of the blood. How important it is that the pancreas secretion should pass in adequate quantity through the liver is shown by the fact that a vascular anastomosis was made between the vessels of part of the pancreas of a normal dog into the circulation of a diabetic dog. There was a reduction of sugar in the blood and almost complete disappearance from the urine only when the venous blood of the pancreas was allowed to pass through the liver by anastomiosis with the splenic vein of the diabetic dog.

Internal secretion is necessary for the kidney cells to do their work properly, for Héden has shown that the bloodsugar may scarcely be diminished at all when this action of the kidney ceases owing to the influx of normal blood. This effect on the kidneys may be either decreased permeability of the cells of the capsules, or it enables the cells of the tubules to do their re-absorption work on the glucose in the glomerular filtrate, or lastly and more probably, it may be owing to the fact that in normal animals the circulating glucose has the internal secretion attached to it, and therefore can be properly metabolised. De Meyer has shown conclusively that this internal secretion of the pancreas is necessary for the storing of glycogen in the liver.

We may conclude then from these experiments that for the hydrolysis of sugar a heat-stable substance is produced by the pancreas. If the concentration of the sugar is greater than $0.2 \%$ in the blood, it is synthesised into glycogen or excreted by the kidneys. Under test tube conditions, e.g., Cohnheim's expcriments, the synthesis evidently only goes 
as far as the production of a disaccharide. It must be remembered that in these experiments of Cohnheim's, and I think his repeaters, the concentration of dextrose was unphysiological-that is, was many times more than could occur under normal conditions in the body. They ought to be repeated, using a concentration of $0.2 \%$.

Before leaving the subject of the tissue metabolism of sugar, it is interesting to note that a similar heat-stable substance can be produced for the metabolism of a foreign sugar introduced into the animal system parenterally. It has been shown that if a solution of cane sugar is injected into a dog it is at first rapidly excreted as cane sugar, but very soon the co-ferment is produced, so that it is converted into glucose, which is either hydrolysed or stored as glycogen, or the superfluity of it excreted by the kidneys.

To sun up, it is clear from the foregoing that the tissue metabolism of sugar is brought about by the interaction of two substances-heat labile complement-like ferment and heat-stable immune-body-like co-ferment.

Shaw-McKenzie and Rosenheim have demonstrated in blood and pancreatic extract a similar co-enzyme for the lipolysis of neutral fat. This is thermo-stable, soluble in glycerin and water, soluble in weak, but insoluble in strong alcohol, and is dialysable. If a glycerin extract of the pancreas is made and filtered through muslin and diluted with water, a milky fluid results. If this fluid is allowed to stand a white precipitate settles. On incubating either the precipitate or supernatant fluid separately with fat no lipolysis occurs, but if the two are mixed together a large amount of lipolysis takes place. The ferment in the precipitate is destroyed by heating to $60^{\circ} \mathrm{C}$., while the co-ferment in the supernatant fluid stands boiling. This co-ferment occurs in large amounts in blood, as we have seen a similar co-enzyme for glycolysis does. I do not know whether experiments similar to Cohnheim's have been done using muscle press-juice, pancreatic extract and neutral fat as a substrate.

Turning now to the question of the tissue digestion of proteins and their anabolism, have we any evidence that a similar co-ferment is present? I think we have. It is well 
known that if any protein antigen is introduced parenterally that a substance not destroyed by heating to $56-60^{\circ}$ C., and absolutely specific for the given protein, is produced, and can be produced, in very large quantities, and that this leads to the hydrolysis of the antigen. Indeed it is nearly certain that it is the partial hydrolysis of the assaulting dose of antigen resulting in the production of some peptonelike substance that is the chief cause of the phenomena of anaphylaxis. In the test-tube this co-ferment produced for foreign red blood corpuscles and certain micro-organisms, for instance, the cholera vibrio, can be easily shown to produce their hydrolysis if sufficient complement, i.e., ferment, is present. In the case of other micro-organisms, the lysis of which is not so obvious, it can be shown that they undergo lysis inside phagocytic cells, for instance, polynuclear leucocytes, if sufficient immune-body, that is co-ferment, is present.

But are these co-ferments just mentioned produced by the pancreas? The negative experiments of MoGowan by the removal of such organs as the spleen, kidney, thyroid by extirpation and other methods show that this does not delay the production of the immune-body on the third day after a rabbit has been injected intravenously with ox-blood corpuscles, and he considers this strong evidence that the immune-body is not formed by these organs. He found that there was no leucocytosis observable in the rabbit after an intravenous, intraperitoneal or subcutaneous injection of ox-blood corpuscles. This further excludes the leucocytic organs, as far as they can be excluded by such a method, in the production of immune-body. McGowan suggests that the liver may be the source of this co-ferment. I think, however, this is unlikely, for, as we have seen in the case of carbohydrates, the liver is dependent on the co-ferments from the pancreas for their metabolism, for I have found that it is impossible, with the exception of certain cases of furunculosis with associated glycosuria, to immunise a diabetic, as one can a non-diabetic patient, against such infections as produce pyorrhœa alveolaris. In diabetics a minute dose of such an antigen is followed by an abnormal general reaction, sometimes also in certain cases a sensation of dir- 
comfort, almost amounting to pain over the pancreatic region suggesting a focal reaction in the gland, and invariably accompanied by an increased excretion of sugar. A curve of the negative phase, unfortunately in these cases seldom followed by a positive phase, can be plotted out by the amount of sugar excreted after a dose. This, of course, might be due either to a general poisoning of the tissues, including the liver and kidneys, but I suggest, especially on account of the increase of focal symptoms in certain cases, that it is more probably owing to a focal reaction in the pancreas.

I think further evidence might be gained on this point if similar experiments to McGowan's were done on dogs with increasing amounts of the pancreas removed or the pancreas transplanted to subcutaneous tissues. It might further be possible to examine the pancreas press-juice of animals immunised against foreign red blood corpuscles or microbes for specific co-ferments. Of the difficulties of immunising a diabetic there can be no question whatever; the explanation of it I have suggested is at any rate a reasonable one.

I think there can be little doubt as to the cells which produce this internal secretion. The source of origin of the cell-islands of Langerhans is not known, but it is impossible to think that these cells with their special blood supply, the increase in size of the islands in certain conditions, e.g., starvation, with their special morphology, staining and granule content, can be merely resting stages of the ordinary cells of the pancreas. The pancreas of a case reported by the late Dr. Scott, of Oxford, appears to my mind conclusive. The case was one of cancer of the head of the pancreas, causing complete occlusion of the ducts, while the rest of the gland was replaced by fat and fibrous tissue, the cell islands alone remained intact-there was no symptom of diabetes. On the other hand, Cecil, of New York, has reported a large series of cases of post-mortems on diabetics, and $87 \%$ of them showed definite gross lesions of the cell islands, and in a considerable number of these the lesions were in the cell islands alone. The remaining 13 per cent. can easily be accounted for by intoxication of the cells without gross morphological change, possibly due to either a 
circulating toxin of whatever kind, for instance, from a gangrenous limb, or the deficiency may be possibly due to the absence of a hormone from the upper intestine, for Hill and Abrahamson have reported certain cases in which glycosuria disappeared or was markedly reduced after the exhibition of duodenal extract by the mouth.

If we accept Beard's theory of the alternation of generations, it is easy to formulate an hypothesis as to the reason for the production of this co-ferment.

The tissues of the sexual generation consist of lævo-proteins, and the fotus as it develops lives at the expense of the phorozoon (larva), whose cells are hypothetically composed of the opposite stereoisomers, while in turn the cells of the larva, that is of the chorionic villi, consisting of dextroprotein, are able to live at the expense of the maternal tissues of the uterus. These cells are able to produce the hydrolysis of their food by means of their ferments without the aid of a co-ferment. When, however, all the tissues of the phorozoon (larva) are used up the foetus has to live if it is to survive on the same stereo-structure as itself. It is just at this period, which Beard calls the " critical period," that is, the period of foetus is born in marsupials and the period in which mammalian placenta becomes functional that the pancreas with its cell-islands also becomes functional. Without it the foetus could not survive, for the co-ferments which it produces adapt the tissue ferments of the foetus to the same stereoisomers as itself, thus enabling them to katabolise and anabolise them.

It is clear that these substances are then in the nature of adapters, and I suggest the word 'adapter' as a generic name for all these products, co-ferments or immune bodies for the metabolism of foreign proteins, foreign red corpuscles, micro-organisms, carbohydrates, and of fats produced by the cell islands of Langerhans of the pancreas. 